\title{
Being Old Does Not Necessarily Mean Being Inactive: Health Profile of Elderly Athletes versus Community-Dwelling Older Adults
}

\author{
Mimi Tse ${ }^{1}$, Anthony Wong1, Vanessa T. C. Wan' \\ ${ }^{1}$ School of Nursing, The Hong Kong Polytechnic University, Hong Kong, China \\ ${ }^{2} \mathrm{M} \& \mathrm{G}$, Prince Margaret Hospital, Hong Kong, China \\ Email: mimi.tse@polyu.edu.hk
}

Received 12 November 2014; revised 11 December 2014; accepted 23 December 2014

Copyright $(2014$ by authors and Scientific Research Publishing Inc.

This work is licensed under the Creative Commons Attribution International License (CC BY). http://creativecommons.org/licenses/by/4.0/

c) (i) Open Access

\begin{abstract}
Introduction: According to the records of the Hong Kong Athletic Gala for the Elderly, some sports events have been won by the same group of elderly participants for several consecutive years. What made these elderly athletes different from others? Method: This was a retrospective quantitative study. The health profile data on a total of 125 elderly participants were collected. 36 and 29 were the winners and losers of the Hong Kong Athletic Gala for the Elderly between 2008 and 2010, respectively. The remaining 60 were non-participants. The non-participants came from six elderly centers in different districts in Hong Kong. Health profile parameters were measured using the Health-Promoting Lifestyle Profile II, which is used to measure healthy behaviors such as physical activity level, nutrition, stress management, health responsibility, interpersonal relations and spiritual growth. Results: About 41.7\% $(n=15)$ and $80.0 \%(n=48)$ of the elderly (mean age = $74 \pm 9.0$ ) in the winner and non-participant groups with chronic diseases. There were significant $(p<0.05)$ differences in fat percentage, mobility, and body mass index among the three groups of elderly. Five out of six domains in the HPLP-II: physical activity, nutrition, interpersonal relations, spiritual growth and health responsibility, were siginificantly different among two groups. Conclusion: It could be concluded that elderly people who had better health status and lifestyle, and who undertook regular exercise, fared better than others in sports events.
\end{abstract}

\section{Keywords}

Older People, Well-Being, Physical Activity, Healthy Lifestyle, Nursing

How to cite this paper: Tse, M., Wong, A. and Wan, V.T.C. (2014) Being Old Does Not Necessarily Mean Being Inactive: Health Profile of Elderly Athletes versus Community-Dwelling Older Adults. International Journal of Clinical Medicine, 5, 1442-1451. http://dx.doi.org/10.4236/ijcm.2014.521182 


\section{Introduction}

The ageing population is a worldwide challenge. According to the World Health Organization in 2002, the population aged 60 and above is increasing more rapidly than other age groups [1]. Hong Kong is no exception to this trend. The longer their life expectancy, the more chronic diseases older adults suffer. In 2000, $71.8 \%$ of older people aged 60 reported at least one type of chronic disease, and $11.8 \%$ had three and $9.9 \%$ four or more [2]. The five most common chronic diseases were hypertension (47.2\%), arthritis (40.6\%), ophthalmic disease (23.9\%), diabetes (20.9\%) and hyperlipidemia (17.9\%). A survey in Hong Kong revealed that $71.8 \%$ of noninstitutionalized elderly aged 60 and above reported having at least one type of chronic condition that caused the great impact on the physical, psychological and social aspects of their lives. Independence and health-related quality of life for the elderly were reduced. Moreover, chronic diseases accounted for about three quarters of total deaths [3]. As a result, growing old was a predictor of poor health, and living with chronic diseases was an outcome of ageing.

According to the records of the Hong Kong Athletic Gala for the Elderly, some sports events have been won by the same group of elderly participants for the past few consecutive years. What makes these elderly athletes different from others, and what are the key elements in their health profile that relate to this demonstration of wellness?

Indeed, physical changes are known to occur in older people: Singh stated that there were changes in heart function like reduced maximal heart rate, tissue elasticity and bone mass [4]. The loss of muscle mass could lead to less muscle strength and functional limitations that would in turn lead to lower physical activity levels [5]. Due to the physiological changes associated with ageing, older people are more susceptible to obesity and chronic diseases.

One of the most important modifiable risk factors is physical activity [6] [7]. Physical activity is defined as any regular participation in light, moderate, and/or vigorous activity. It may occur within a planned and monitored program for the sake of fitness and health, or incidentally as a part of daily life or leisure activities [8]-[10]. Recently, the health benefits of physical activity have been fully demonstrated. Overweight and obesity are the major risk factors for many chronic diseases, so physical activity can minimize the risk of being overweight and obese. In addition, evidence showed that physical activity played an important role in preventing chronic diseases such as coronary heart disease, stroke, hypertension, type 2 diabetes mellitus, breast cancer, colon cancer, and osteoporosis [11]. In general, older people believe that physical activity can promote physical health in order to make their bones stronger and to help them to better control chronic diseases such as blood pressure and blood sugar levels [12]. Also, the cardiovascular and respiratory function could be improved and weight was well controlled [13]. Further, physical activity was crucial in reducing overall morbidity and mortality [14]. Thus, promoting physical activity is global importance for community-dwelling older adults, including those with chronic diseases, in order to optimize their functional level and enable them to engage in a healthy life.

Besides the physical benefits, several cross-sectional studies have shown that symptoms of depression and anxiety tend to occur more frequently in the physically inactive than in active subjects. Regular physical activity could be associated with reduced depressive symptoms and clinical depression among older people in various studies [15]-[17]. Lampinen et al. reported that low baseline physical activity or people who reduced their baseline physical activity intensity were at greater risk for depression [18]. In addition, studies showed that older people felt happier and more relaxed after physical activity, which could improve their mental well-being. More involvement in physical activity was demonstrated to result in better life satisfaction [19]. Furthermore, in terms of social life, group involvement in physical activity can limit loneliness and boredom and enable people to develop better friendships [12].

Although it is widely accepted that regular physical activity has advantages for physical health, mental well-being and social life, lack of physical exercise is still identified as the fourth leading risk factor for global mortality, causing 3.2 million deaths [20]. However, older people in Hong Kong are failing to address the situation. And there were $8.3 \%$ and $16.6 \%$ of those aged 65 - 75 and above respectively who did not walk for 10 minutes a day. Meanwhile, $18.7 \%$ and $30.9 \%$ aged $65-75$ and above respectively were classified as engaging in "low" levels of physical activity. A few older people had an optimal level of physical activity, but the accuracy of the stated frequency and amount achieved was in doubt [21].

Therefore, the aims of this study are to compare the health profile measurements of the two groups of older people and identify the differences between the winners of Hong Kong Athletic Gala and the rest. 


\section{Method}

\subsection{Design and Sampling}

This research was a non-experimental, quantitative cross-sectional exploratory retrospective study.

After gaining ethical approval, the Yuen Yuen Elderly Center was approached and invited. The Yuen Yuen Elderly Center then tried to contact the other 25 elderly centers that had participated in the Hong Kong Athletic Gala for Elderly from 2008-2010. A total of 26 elderly centers were considered to be the target population.

Convenience sampling was adopted for the study. It was estimated that a minimum of 104 of the total samples had to be recruited, and that the participant and non-participant groups should be of equal weighting. Taking into account a dropout rate of $20 \%$, a total of 125 subjects included 65 in participant group and 60 in non-participant group were recruited from 6 centers finally [22].

In the participants' group, the eligibility criteria were as follows: aged over 55; member of the elderly centers; participated in the Hong Kong Athletes Gala from 2008-2010; and able to communicate in Cantonese, Putonghua or English. In the non-participant group, the eligibility criteria were same as the participants' group except they did not join the Hong Kong Athletes Gala from 2008-2010. Those who were cognitively impaired, including those with dementia, or disabled, including the blind, deaf and immobile, were excluded in this study.

\subsection{Procedure}

\subsubsection{Research Setting}

This study was divided into two phases. In Phase I, samples from six elderly centers were invited to carry out a mini health check followed by a face-to-face interview. A one-to-one approach was adopted for the whole process, and a consultation session on health status was also provided at the end. In Phase II, dissemination of the results was held after the data analysis in the elderly centers. A sharing session was conducted in small groups for those who had joined Phase I.

\subsubsection{Data Collection Procedure}

The staff of each of the elderly centers was contacted in advance. The researcher approached all elderly members that fit the inclusion criteria and invited them to join the study. Each subject was asked to sign a written consent form, and a Chinese information sheet was explained and distributed to ensure their understanding. Standard wordings were established and all researchers had to follow a strict protocol during the interviews to minimize variations.

First, demographic information was collected after participants had undergone the mini health check, including weight, height, body fat percentage, blood pressure and timed up-and-go test. Next, Health-Promoting Lifestyle Profile II was collected.

\subsubsection{Instruments of Outcome Measures}

Demographic data including gender, age, marital status, educational level, family relations, previous occupation, personal health condition, living environment, transportation, physical activity level, and pain perception from two groups of older people. A mini health check consisting of measuring body mass index (BMI), fat percentage, blood pressure, mobility (assessed by timed up-and-go test) and health habits (exercise, smoking and drinking habit) was carried out in order to encourage the elderly to join our research before going into the face-to-face interview. The data of the mini health check would be used merely as a reference for the health status of the elderly. The face-to-face interview was conducted to explore the elderly participants' lifestyle characteristics (assessed by the Health-Promoting Lifestyle Profile II).

The Health-Promoting Lifestyle Profile II [23] consists of 52 items in six domains, namely health responsibility, physical activity, nutrition, spiritual growth, interpersonal relations, and stress management. Items are scored as never $(\mathrm{N})=1$, sometimes $(\mathrm{S})=2$, often $(\mathrm{O})=3$, routinely $(\mathrm{R})=4$. A score for overall health-promoting lifestyle is obtained by calculating a mean of the individual's responses to all 52 items; six subscale scores are obtained similarly by calculating a mean of the responses to the subscale items. A Chinese version of the HealthPromoting Lifestyle Profile II was used. Construct validity was supported by factor analysis, which confirmed a six-dimensional structure for a health-promoting lifestyle, by convergence with the Personal Lifestyle Questionnaire $(r=0.678)$; the alpha coefficient of internal consistency for the total scale was 0.943 ; the test-retest stability coefficient for the total scale was 0.892 [24]. 


\subsection{Data Analysis}

Several statistical methods were used in data analysis. Descriptive statistical analysis of the quantitative data was conducted using the Statistical Package for Social Science (SPSS) for Windows, version 17.0. The Chisquared test was used to analyze the differences in the demographic data (except physical activity level and pain level) between groups. The Mann-Whitney $U$ test was used to analyze the differences in demographic data (physical activity level, pain level, smoking and drinking habit) and HPLP-II for elderly. A $p$-value $<0.05$ was considered statistically significant.

\section{Results}

\subsection{Demographic Data}

There were 125 older people (86 females and 39 males) participated in the study. The ages ranged from 55 to 92 . There were 52\% $(n=65)$ of the elderly subjects had participated in the Athletic Gala for the Elderly since 2008, while $48 \%(n=60)$ were non-participants. Around $90 \%$ of them were satisfied with their living environment and transportation. In the participant group, 64.6\% were married and 32.3\% still lived with their spouse and children. Over $90 \%$ of them had primary education and nearly $60 \%$ of them were non-labour before retirement.

Significant differences were found in gender, family status, marital status, education level and previous occupation, whereas no significant differences were found between the two groups in terms of family relationship, living environment and transportation of living place (Table 1).

\subsection{Health Characteristics and Lifestyle Habits}

About $60 \%$ of the subjects suffered from chronic diseases, among which hypertension (43.2\%), musculoskeletal disorders (16.0\%) and diabetes (13.6\%) were the most common; more cases were reported in the non-participant group.

Table 2 shows that significant differences were found in the presence of chronic disease, receiving medical appointments and long-term medication, number of chronic diseases, and having two chronic diseases such as hypertension and a gastrointestinal disease $(p<0.05)$. In the participant group, $47.7 \%$ suffered from chronic diseases. The means of fat percentage, body mass index and timed up-and-go were nearly $28.9 \pm 6.26,23.8 \pm$ 2.62 and $8.84 \pm 2.70$ respectively. In the non-participant group, $80 \%$ suffered from chronic diseases. Nearly $40 \%$ of the sufferers had more than one type of chronic illness, in some cases even up to more than three types. The means of fat percentage, body mass index and timed up-and-go were nearly 32.1 $\pm 6.26,27.5 \pm 2.62$ and $10.4 \pm$ 2.70 respectively.

There was no significant difference between the participant and non-participant groups in the health status characteristics of presence of pain, pain intensity, and past health history such as heart disease, diabetes mellitus, respiratory disease $(p>0.05)$.

In Table 3, there were significant differences in duration, frequency of physical activity $(p<0.05)$. Nearly $80 \%$ of the participant group performed physical activity daily for more than 30 minutes at a time, whereas just half of the non-participant group performed physical activity daily and only $10 \%$ did so for more than 30 minutes each time. In addition, there was no significant difference between the participant and non-participant groups in the unhealthy habits of smoking and drinking $(p>0.05)$.

\subsection{Health Promoting Lifestyle Profile II}

Participants had higher mean scores in all domains in HPLP-II than non-participants. Significant differences $(p<$ 0.001) were found in five domains, that is, all except stress management (Table 4).

\section{Discussion}

In this study, non-participants were found to have relatively high BMI, higher fat percentage, and poor gait. This echoes previous studies, which found that physical inactivity was associated with obesity and reduction in energy expenditure. Therefore, an increase, or at least a maintained level of activity, is thought to be a major solution for obesity after retirement from active work [25] [26]. In addition, functional ability unavoidably declines with age, however flexibility, agility, balance, muscle strength and endurance can be improved by staying physical 
Table 1. Demographic characteristics of elderly.

\begin{tabular}{|c|c|c|c|c|c|}
\hline \multirow[t]{2}{*}{ Demographic characteristics } & \multirow{2}{*}{$\begin{array}{c}\text { Total } \\
(\mathrm{n}=125)\end{array}$} & \multirow{2}{*}{$\begin{array}{l}\text { Group participants } \\
\text { (n=65) } \\
\mathrm{n}(\%)\end{array}$} & \multirow{2}{*}{$\begin{array}{l}\text { Non-participants } \\
(\mathrm{n}=60) \\
\mathrm{n}(\%)\end{array}$} & \multicolumn{2}{|c|}{ Test } \\
\hline & & & & $p$-value $\alpha$ & $p$-value $\beta$ \\
\hline Age (mean \pm S.D.) & $74.36 \pm 9.00$ & $70.77 \pm 7.63$ & $78.25 \pm 8.82$ & $<0.001^{* *}$ & \\
\hline $55-64$ & $16(12.8)$ & $11(16.9)$ & $5(8.3)$ & & \\
\hline $65-74$ & $52(41.6)$ & $33(50.8)$ & $19(31.7)$ & & \\
\hline $75-84$ & $33(26.4)$ & $17(26.2)$ & $16(26.7)$ & & \\
\hline$>84$ & $24(19.8)$ & $4(6.2)$ & $20(33.3)$ & & \\
\hline Gender & & & & & $0.020^{*}$ \\
\hline Male & $39(31.2)$ & $25(64.1)$ & $14(35.9)$ & & \\
\hline Female & $86(68.8)$ & $40(46.5)$ & $46(53.5)$ & & \\
\hline Family status & & & & & $0.005^{*}$ \\
\hline Live alone & 27 (21.6) & $12(18.5)$ & $15(25.0)$ & & \\
\hline Live with partner & $28(22.4)$ & $16(26.6)$ & $12(20.0)$ & & \\
\hline Live with sons and/or daughters & $29(23.2)$ & $13(20.0)$ & $16(26.7)$ & & \\
\hline Live with partner, sons and/or daughters & $26(20.8)$ & $21(32.3)$ & $5(8.3)$ & & \\
\hline Live with relatives or friends & $13(10.4)$ & $3(4.6)$ & $10(16.7)$ & & \\
\hline Others & $2(1.6)$ & $0(0.0)$ & $2(3.3)$ & & \\
\hline Family relationship & & & & 0.803 & \\
\hline Bad & $3(2.4)$ & $1(1.5)$ & $2(3.3)$ & & \\
\hline Average & $33(26.4)$ & $17(26.2)$ & $16(26.7)$ & & \\
\hline Good & $62(49.6)$ & 35 (53.8) & $27(45.0)$ & & \\
\hline Very good & 27 (21.6) & $12(18.5)$ & $15(25.0)$ & & \\
\hline Marital status & & & & & $0.006^{*}$ \\
\hline Single & $6(4.8)$ & $2(3.1)$ & $4(6.7)$ & & \\
\hline Married & $62(49.6)$ & $42(64.6)$ & $20(33.3)$ & & \\
\hline Divorced & $1(0.8)$ & $1(1.5)$ & $0(0.0)$ & & \\
\hline Separated & $1(0.8)$ & $0(0.0)$ & $1(1.7)$ & & \\
\hline Widowed & $55(44.0)$ & $20(30.8)$ & 35 (58.3) & & \\
\hline Education level & & & & $<0.001^{* *}$ & \\
\hline Uneducated & 27 (21.6) & $5(7.7)$ & $22(36.7)$ & & \\
\hline Primary school level & $30(24.0)$ & $13(20.0)$ & $17(28.3)$ & & \\
\hline Secondary school level & 37 (29.6) & $28(43.1)$ & $9(15.0)$ & & \\
\hline Undergraduate or above & $31(24.8)$ & $19(29.2)$ & $12(20.0)$ & & \\
\hline Previous occupation & & & & & $0.031^{*}$ \\
\hline Labor & $68(54.4)$ & $31(47.7)$ & 37 (61.7) & & \\
\hline Civil & $15(12)$ & $9(13.8)$ & $6(10.0)$ & & \\
\hline Profession & 27 (21.6) & $20(30.8)$ & $7(11.7)$ & & \\
\hline Housewife & $15(12)$ & $5(7.7)$ & $10(16.7)$ & & \\
\hline Living environment & & & & & 0.058 \\
\hline No comment & $11(8.8)$ & $4(6.2)$ & $7(11.7)$ & & \\
\hline Satisfied & $109(87.2)$ & $56(86.2)$ & $53(88.3)$ & & \\
\hline Unsatisfied & $5(4.0)$ & $5(7.7)$ & $0(0.0)$ & & \\
\hline Transportation to place of residence & & & & & 0.164 \\
\hline No comment & $6(4.8)$ & $2(3.1)$ & $4(6.7)$ & & \\
\hline Satisfied & $116(92.8)$ & $60(92.3)$ & $56(93.3)$ & & \\
\hline Unsatisfied & $3(2.4)$ & $3(4.6)$ & $0(0.0)$ & & \\
\hline
\end{tabular}

Note: $\alpha$ : Mann-Whitney U test was used for comparison between groups. $\beta$ : Chi-squared test was used for comparison between groups. ${ }^{* *} p<0.001 ;{ }^{*} p<$ 0.05 was considered statistically significant. 
Table 2. Health characteristics of elderly in the study.

\begin{tabular}{|c|c|c|c|c|c|}
\hline \multirow{2}{*}{ Health characteristics } & \multirow{2}{*}{$\begin{array}{c}\text { Total } \\
(\mathrm{n}=125) \\
\mathrm{n}(\%)\end{array}$} & \multirow{2}{*}{$\begin{array}{l}\text { Group participants } \\
\qquad(\mathrm{n}=65) \\
\mathrm{n}(\%)\end{array}$} & \multirow{2}{*}{$\begin{array}{c}\text { Non-participants } \\
\text { (n = 60) } \\
\mathrm{n}(\%)\end{array}$} & \multicolumn{2}{|c|}{ Test } \\
\hline & & & & $p$-value $\alpha$ & $p$-value $\beta$ \\
\hline Presence of chronic disease & & & & & $<0.001^{* *}$ \\
\hline Yes & $78(62.4)$ & $31(47.7)$ & $48(80.0)$ & & \\
\hline No & $47(37.6)$ & $34(52.3)$ & $12(20.0)$ & & \\
\hline Number of chronic diseases & & & & $<0.001^{* *}$ & \\
\hline No chronic disease & $46(36.8)$ & $34(52.3)$ & $12(20.0)$ & & \\
\hline One chronic disease & $40(32.0)$ & $15(23.1)$ & 25 (41.7) & & \\
\hline Two chronic diseases & $30(24.0)$ & $16(24.6)$ & $14(23.3)$ & & \\
\hline Three chronic diseases & $5(4.0)$ & $0(0)$ & $5(8.3)$ & & \\
\hline Three or more chronic diseases & $4(3.2)$ & $0(0)$ & $4(6.7)$ & & \\
\hline \multicolumn{6}{|l|}{ Types of chronic disease } \\
\hline Hypertension & $54(43.2)$ & $21(32.3)$ & $33(55.0)$ & & $0.011^{*}$ \\
\hline Diabetes mellitus & $17(13.6)$ & $9(13.8)$ & $8(13.3)$ & & 0.933 \\
\hline Coronary heart disease & $9(7.2)$ & $2(3.1)$ & $7(11.7)$ & & 0.063 \\
\hline Eye disorders & $5(4.0)$ & $2(3.1)$ & $3(5.0)$ & & 0.584 \\
\hline Musculoskeletal disorders & $20(16.0)$ & $7(10.8)$ & $13(21.7)$ & & 0.097 \\
\hline Gastrointestinal diseases & $6(4.8)$ & $0(0.0)$ & $6(10.0)$ & & $0.009^{*}$ \\
\hline Thyroid disorders & $3(2.4)$ & $1(1.5)$ & $2(3.3)$ & & 0.512 \\
\hline Ear, nose and throat diseases & $3(2.4)$ & $1(1.5)$ & $2(3.3)$ & & 0.512 \\
\hline Respiratory diseases & $3(2.4)$ & $1(1.5)$ & $2(3.3)$ & & 0.512 \\
\hline Osteoporosis & $2(1.6)$ & $1(1.5)$ & $1(1.7)$ & & 0.954 \\
\hline Depression & $2(1.6)$ & $0(0.0)$ & $2(3.3)$ & & 0.138 \\
\hline History of stroke & $1(0.8)$ & $1(1.5)$ & $0(0.0)$ & & 0.335 \\
\hline Sleep disorders & $2(1.6)$ & $0(0.0)$ & $2(3.3)$ & & 0.138 \\
\hline History of cancer & $1(0.8)$ & $0(0.0)$ & $1(1.7)$ & & 0.296 \\
\hline Epilepsy & $2(1.6)$ & $0(0.0)$ & $2(3.3)$ & & 0.138 \\
\hline Parkinson's disease & $1(0.8)$ & $1(1.5)$ & $0(0.0)$ & & 0.335 \\
\hline $\begin{array}{l}\text { Receiving medical appointments } \\
\text { and long-term medication }\end{array}$ & & & $<0.001^{* *}$ & & \\
\hline Yes & $78(62.4)$ & $30(46.2)$ & $48(80.0)$ & & \\
\hline No & $47(37.6)$ & 35 (53.8) & $12(20.0)$ & & \\
\hline Presence of pain & & & & & 0.354 \\
\hline Yes & $53(42.4)$ & 25 (38.5) & $28(46.7)$ & & \\
\hline \multirow[t]{2}{*}{ No } & $72(27.6)$ & $40(61.5)$ & $32(53.3)$ & & \\
\hline & Mean \pm S.D. & Mean \pm S.D. & Mean \pm S.D. & & \\
\hline Pain intensity (scale: 0 - 10) & $2.294 \pm 3.233$ & $1.846 \pm 2.863$ & $2.780 \pm 3.551$ & 0.120 & \\
\hline Fat percentage (\%) & $30.402 \pm 6.359$ & $28.849 \pm 6.256$ & $32.085 \pm 6.082$ & $0.005^{*}$ & \\
\hline Timed up-and-go (seconds) & $9.581 \pm 3.584$ & $8.842 \pm 2.690$ & $10.382 \pm 4.229$ & $0.049^{*}$ & \\
\hline Body mass index $\left(\mathrm{kg} / \mathrm{m}^{2}\right)$ & $25.576 \pm 5.478$ & $23.789 \pm 2.621$ & $27.511 \pm 6.950$ & $0.021^{*}$ & \\
\hline Systolic blood pressure (mmHg) & $128.848 \pm 16.462$ & $127.292 \pm 15.279$ & $130.533 \pm 17.628$ & 0.370 & \\
\hline Diastolic blood pressure (mmHg) & $73.920 \pm 11.201$ & $77.354 \pm 11.284$ & $70.200 \pm 9.925$ & $<0.001^{* *}$ & \\
\hline
\end{tabular}

Note: $\alpha$ : Mann-Whitney $\mathrm{U}$ test was used for comparison between groups. $\beta$ : Chi-squared test was used for comparison between groups. ${ }^{* *} p<0.001 ;{ }^{*} p<$ 0.05 was considered statistically significant. 
Table 3. Lifestyle habits of elderly in the study.

\begin{tabular}{|c|c|c|c|c|c|}
\hline \multirow{2}{*}{ Lifestyle characteristics } & \multirow{2}{*}{$\begin{array}{c}\text { Total } \\
(\mathrm{n}=125) \\
\mathrm{n}(\%)\end{array}$} & \multirow{2}{*}{$\begin{array}{l}\text { Group participants } \\
\qquad(\mathrm{n}=65) \\
\mathrm{n}(\%)\end{array}$} & \multirow{2}{*}{$\begin{array}{c}\text { Non-participants } \\
\text { (n = 60) } \\
n(\%)\end{array}$} & \multicolumn{2}{|c|}{ Test } \\
\hline & & & & $p$-value $\alpha$ & $p$-value $\beta$ \\
\hline Duration of exercise & & & & $<0.001^{* *}$ & \\
\hline No exercise & $0(0)$ & $0(0)$ & $5(8.3)$ & & \\
\hline$\leq 10$ minutes & $1(0.8)$ & $0(0)$ & $6(10.0)$ & & \\
\hline 10 to 20 minutes & $10(8.0)$ & $7(10.8)$ & $33(55.0)$ & & \\
\hline 20 to 30 minutes & $10(8.0)$ & $7(10.8)$ & $10(16.7)$ & & \\
\hline$\geq 30$ minutes & $104(83.2)$ & $51(78.5)$ & $6(10.0)$ & & \\
\hline Frequency of exercise & & & & $0.001^{*}$ & \\
\hline No exercise & $9(7.2)$ & $0(0)$ & $9(15.0)$ & & \\
\hline$\leq 3$ times per week & $16(12.8)$ & $4(6.2)$ & $12(20.0)$ & & \\
\hline$\geq 3$ times per week & $18(14.4)$ & $11(16.9)$ & $7(11.7)$ & & \\
\hline Daily & $82(65.6)$ & 50 (76.9) & $32(53.3)$ & & \\
\hline Smoking habit & & & & & 0.060 \\
\hline Never & $110(88.0)$ & $53(81.5)$ & $57(95.0)$ & & \\
\hline Quit & $12(9.6)$ & $10(15.4)$ & $2(3.3)$ & & \\
\hline Yes & $3(2.4)$ & $2(3.1)$ & $1(1.7)$ & & \\
\hline Drinking habit & & & & & 0.483 \\
\hline Never & $103(82.4)$ & 51 (78.5) & 52 (86.7) & & \\
\hline Quit & $8(6.4)$ & $5(7.7)$ & $3(5.0)$ & & \\
\hline Yes & $14(11.2)$ & $9(13.8)$ & $5(8.3)$ & & \\
\hline
\end{tabular}

Note: $\alpha$ : Mann-Whitney U test was used for comparison between groups. $\beta$ : Chi-squared test was used for comparison between groups. ${ }^{* * *} p<0.001 ;{ }^{*} p<$ 0.05 was considered statistically significant.

Table 4. HPLP-II mean score in different lifestyle domains in the study.

\begin{tabular}{ccccc}
\hline $\begin{array}{c}\text { Mean score } \\
\text { (highest mark =4) }\end{array}$ & Total $(\mathrm{n}=125)$ & Group participants $(\mathrm{n}=65)$ & Non-participants $(\mathrm{n}=60)$ & Test \\
\cline { 2 - 5 } & Mean \pm SD & Mean \pm SD & Mean \pm SD & $p$-value \\
\hline Overall HPLP II & $2.57 \pm 0.45$ & $2.85 \pm 0.31$ & $2.28 \pm 0.39$ & $<0.001^{*}$ \\
Physical activity & $2.37 \pm 0.70$ & $2.77 \pm 0.42$ & $1.93 \pm 0.70$ & $<0.001^{*}$ \\
Nutrition & $2.703 \pm 0.558$ & $3.009 \pm 0.401$ & $2.372 \pm 0.514$ & $<0.001^{* *}$ \\
Interpersonal relations & $2.592 \pm 0.526$ & $2.858 \pm 0.445$ & $2.303 \pm 0.453$ & $<0.001^{* *}$ \\
Stress management & $2.627 \pm 0.452$ & $2.654 \pm 0.480$ & $2.597 \pm 0.421$ & 0.516 \\
Spiritual growth & $2.610 \pm 0.672$ & $2.781 \pm 0.596$ & $2.263 \pm 0.485$ & $<0.001^{* *}$ \\
Health responsibility & $2.532 \pm 0.602$ & $2.781 \pm 0.596$ & $2.263 \pm 0.485$ & $<0.001^{* *}$
\end{tabular}

Note: Mann-Whitney U test was used for comparison between groups. ${ }^{* *} p<0.001 ;{ }^{*} p<0.05$ was considered statistically significant.

active, potentially resulting in enhancing the individual's mobility and achieving a better gait [27].

Non-participants became fall victims with more chronic diseases, especially hypertension, musculoskeletal diseases, diabetes mellitus. This result is not surprising given that most of the non-participants were found to be obese. Lower levels of physical activity were quite consistently associated with a higher blood pressure level and 30\% higher risk of developing hypertension [25]. A high prevalence of musculoskeletal disorders such as joint pain was related to physical inactivity in various studies [28] [29]. 
The lower mean scores in overall HPLP-II in the non-participant group showed that they were leading a relatively unhealthy lifestyle, especially in the domains of physical activity. Health responsibility was found rather unsatisfactory in the non-participant group because most of them were widowed and had a lower education level. Health responsibility was believed to be associated with education level and marital status. A higher education level provided people with more knowledge of the advantages of adopting a healthier lifestyle behavior comprising the regular performance of physical activity [30]. In addition, married individuals were inclined to gain more spousal support that involved advice giving, assistance, reassurance and empathic listening. Married individuals also had a higher availability, amount and quality of social support than those were unmarried or widowed, since the latter often lacked support, especially spousal support [30] [31]. Marriage also prevents people from indulging in risky behaviors, since they have responsibilities and are expected to play a particular role in the family; this therefore promotes a healthier lifestyle, including participating in physical activity and adopting a healthier diet [30]. With poor health responsibility, non-participants were also frequently found to adopt a somewhat unhealthy lifestyle, for example in the nutritional and interpersonal aspects.

In the study, lower mean scores in interpersonal relations revealed that the non-participants were unable to achieve a sense of intimacy and meaningful relationship with others [24]. Social support from friends is often highlighted as having an association with participation in physical activity [32].

This study had several limitations. First, the participant recruited locations were limited in the elderly centre, which may not be enough generalizability. Second, there were nearly two fold of female participants as compare with male, thus the findings may represent more to the female perspective.

\section{Conclusions}

Based on the results obtained from this study, it can be concluded based on the elderly people who participated in the Athletic Gala that being an athlete seems to result in a higher physical activity level, better health status, and healthier lifestyle regarding physical activity. Not just increasing physical activity but also leading a healthy lifestyle is the key to being healthier.

The findings of this study provide a descriptive profile of the health-related lifestyle and physical activity pattern of the elderly in Hong Kong and a foundation for the development of health promotion programmes among the elderly to enhance their engagement in physical activity and encourage them to adopt a better health-related lifestyle. This study can provide an insight for nurses in community-dwelling elderly health promotion. It also enhances their knowledge in gerontological health based on physical activity and a healthy lifestyle. When promoting physical activity among the elderly in the community, elements of spiritual growth, interpersonal relations, nutrition and motivation can be considered or integrated to enhance its effectiveness. For greatest benefit, health promotion can be offered not only to non-participants in the elderly centers, but also to the elderly in the community at large.

\section{Acknowledgements}

The author would like to thank all the study participants. The Hong Kong Polytechnic University supported the study. No financial arrangements had been made with any organization or company at the time of this paper's submission.

\section{Conflicts of Interest}

None declared.

\section{References}

[1] WHO (2002) Active Ageing: A Policy Framework. WHO’s Ageing and Life Course Programme, Madrid.

[2] Department of Health (2004) Tropical Health Report No. 3: Elderly Health. Printing Department, Hong Kong Special Administrative Region.

[3] Lima, M., Barros, M., César, C., Goldbaum, M., Carandina, L. and Ciconelli, R. (2009) Impact of Chronic Disease on Quality of Life among the Elderly in the State of São Paulo, Brazil: A Population-Based Study. Revista Panamericana de Salud Pública, 25, 314-321. http://dx.doi.org/10.1590/S1020-49892009000400005

[4] Singh, N. (2002) Exercise Comes of Age: Rationale and Recommendations for a Geriatric Exercise Prescription. 
Journal of Gerontology, 57A, 262-282. http://dx.doi.org/10.1093/gerona/57.5.M262

[5] Schuit, A. (2006) Physical Activity, Body Composition and Healthy Ageing. Science and Sports, 21, $209-213$. http://dx.doi.org/10.1016/j.scispo.2006.06.004

[6] WHO (2005) Preventing Chronic Diseases: A Vital Investment: WHO Global Report. Department of Chronic Diseases and Health Promotion, Geneva.

[7] Wendel-Vos, W.W., Droomers, M.M., Kremers, S.S., Brug, J.J. and van Lenthe, F.F. (2007) Potential Environmental Determinants of Physical Activity in Adults: A Systematic Review. Obesity Reviews, 8, 425-440. http://dx.doi.org/10.1111/j.1467-789X.2007.00370.x

[8] Bouchard, C., Shepard, R.J., Stephens, T., Sutton, J.R. and McPherson, B.D. (1990) Exercise, Fitness, and Health. Human Kinetics Books, Champaign.

[9] Dishman, R.K. (1988) Exercise Adherence: Its Impact on Public Health. Human Kinetics Books, Champaign.

[10] US Department of Health and Human Services (1991) Healthy People 2000: National Health Promotion and Disease Prevention Objectives. US Government Printing Office, Washington DC.

[11] Warburton, D.E., Katzmarzyk, P.T., Rhodes, R.E. and Shephard, R.J. (2007) Evidence-Informed Physical Activity Guidelines for Canadian Adults. Applied Physiology, Nutrition, and Metabolism, 32, S16-S68. http://dx.doi.org/10.1139/H07-123

[12] Lin, Y.C., Huang, L.H., Young, H.M. and Chen, Y.M. (2007) Beliefs about Physical Activity: Focus Group Results of Chinese Community Elderly in Seattle and Taipei. Geriatric Nursing, 28, 236-244. http://dx.doi.org/10.1016/j.gerinurse.2006.12.003

[13] Mancuso, C.A., Perna, M., Sargrent, A.B. and Salmon, J.E. (2011) Perceptions and Measurements of Physical Activity in Patients with Systemic Lupus Erythematosus. Lupus, 20, 231-242. http://dx.doi.org/10.1177/0961203310383737

[14] Brunet, J. and Sabiston, C.M. (2011) Exploring Motivation for Physical Activity across the Adult Lifespan. Psychology of Sport and Exercise, 12, 99-105. http://dx.doi.org/10.1016/j.psychsport.2010.09.006

[15] Bäckmand, H.M., Kaprio, J., Kujala, U.M. and Sarna, S. (2009) Physical Activity, Mood and the Functioning of Daily living: A Longitudinal Study among Former Elite Athletes and Referents in Middle and Old Age. Archives of Gerontology and Geriatrics, 48, 1-9. http://dx.doi.org/10.1016/j.archger.2007.09.002

[16] Bäckmand, H., Kaprio, J., Kujala, U. and Sarna, S. (2003) Influence of Physical Activity on Depression and Anxiety of Former Elite Athletes. International Journal of Sports Medicine, 24, 609-619. http://dx.doi.org/10.1055/s-2003-43271

[17] Krits-Silverstein, D., Barrett-Connor, E. and Corbeau, C. (2001) Cross-Sectional and Prospective Study of Exercise and Depressed Mood in the Elderly. American Journal of Epidemiology, 153, 596-603. http://dx.doi.org/10.1093/aje/153.6.596

[18] Lampinen, P., Heikkinen, R.L. and Ruoppila, I. (2000) Changes in Intensity of Physical Exercise as Predictors of Depressive Symptoms among Older Adults: An Eight-Year Follow-Up. Preventive Medicine, 30, 371-380. http://dx.doi.org/10.1006/pmed.2000.0641

[19] Stathi, A., Fox, K.R. and McKenna, J. (2002) Physical Activity and Dimensions of Subjective Well-Being in Older Adults. Journal of Aging and Physical Activity, 10, 79-92.

[20] WHO (2011) 10 Facts on Physical Activity. http://www.who.int/features/factfiles/physical_activity/en/index.html

[21] Department of Health (2006) Action Plan to Promote Healthy Diet and Physical Activity Participation in Hong Kong. http://www.dh.gov.hk/english/pub_rec/pub_rec_ar/pub_rec_ncd_ap.html

[22] Newcombe, R.G. (1998) Two-Sided Confidence Intervals for the Single Proportion: Comparison of Seven Methods. Statistics in Medicine, 17, 857-872. http://dx.doi.org/10.1002/(SICI)1097-0258(19980430)17:8<857::AID-SIM777>3.0.CO;2-E

[23] Walker, S.N., Sechrist, K.R. and Pender, N.J. (1987) The Health-Promoting Lifestyle Profile: Development and Psychometric Characteristics. Nursing Research, 36, 76-81. http://dx.doi.org/10.1097/00006199-198703000-00002

[24] Walker, S.N. and Hill-Polerecky, D.M. (1996) Psychometric Evaluation of the Health-Promoting Lifestyle Profile II. Unpublished Manuscript, University of Nebraska Medical Centre, Omaha.

[25] Vuori, I. (2007) Physical Activity and Health: Metabolic and Cardiovascular Issues. Advances in Physiotherapy, 9, 50-64. http://dx.doi.org/10.1080/14038190701395887

[26] Haslam, D. (2008) Understanding Obesity in the Older Person: Prevalence and Risk Factors. British Journal of Community Nursing, 13, 115-122. http://dx.doi.org/10.12968/bjcn.2008.13.3.28675

[27] Lisa, M. (2007) Cognitive Decline: Is There a Protective Role for Nutrition and Physical Activity? British Journal of Community Nursing, 14, 142-146.

[28] Holth, H.S., Buchardt Werpen, H.K., Zwart, J.A. and Hagen, K. (2008) Physical Inactivity Is Associated with Chronic 
Musculoskeletal Complaints 11 Years Later: Results from the Nord-Trøndelag Health Study. BMC Musculoskeletal Disorders, 9, 159-165. http://dx.doi.org/10.1186/1471-2474-9-159

[29] Larsson, M.E.H. and Nordholm, L.A. (2008) Responsibility for Managing Musculoskeletal Disorders-A Cross-Sectional Postal Survey of Attitudes. BMC Musculoskeletal Disorders, 9, 110-121. http://dx.doi.org/10.1186/1471-2474-9-110

[30] Ochieng, B.M. (2008) Factors Affecting Choice of a Healthy Lifestyle: Implications for Nurses. British Journal of Community Nursing, 11, 78-82. http://dx.doi.org/10.12968/bjcn.2006.11.2.20445

[31] Hankonen, N., Absetz, P., Ghisletta, P., Renner, B. and Uutela, A. (2010) Gender Differences in Social Cognitive Determinants of Exercise Adoption. Psychology and Health, 25, 55-69. http://dx.doi.org/10.1080/08870440902736972

[32] Grant-Savela, S.D. (2010) Active Living among Older Residents of a Rural Naturally Occurring Retirement Community. Journal of Applied Gerontology, 29, 531-553. http://dx.doi.org/10.1177/0733464809341470 
Scientific Research Publishing (SCIRP) is one of the largest Open Access journal publishers. It is currently publishing more than 200 open access, online, peer-reviewed journals covering a wide range of academic disciplines. SCIRP serves the worldwide academic communities and contributes to the progress and application of science with its publication.

Other selected journals from SCIRP are listed as below. Submit your manuscript to us via either submit@scirp.org or Online Submission Portal.
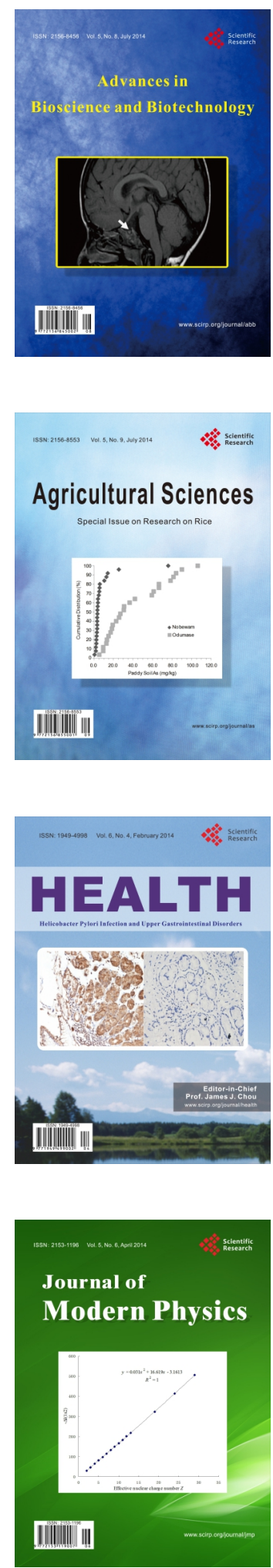
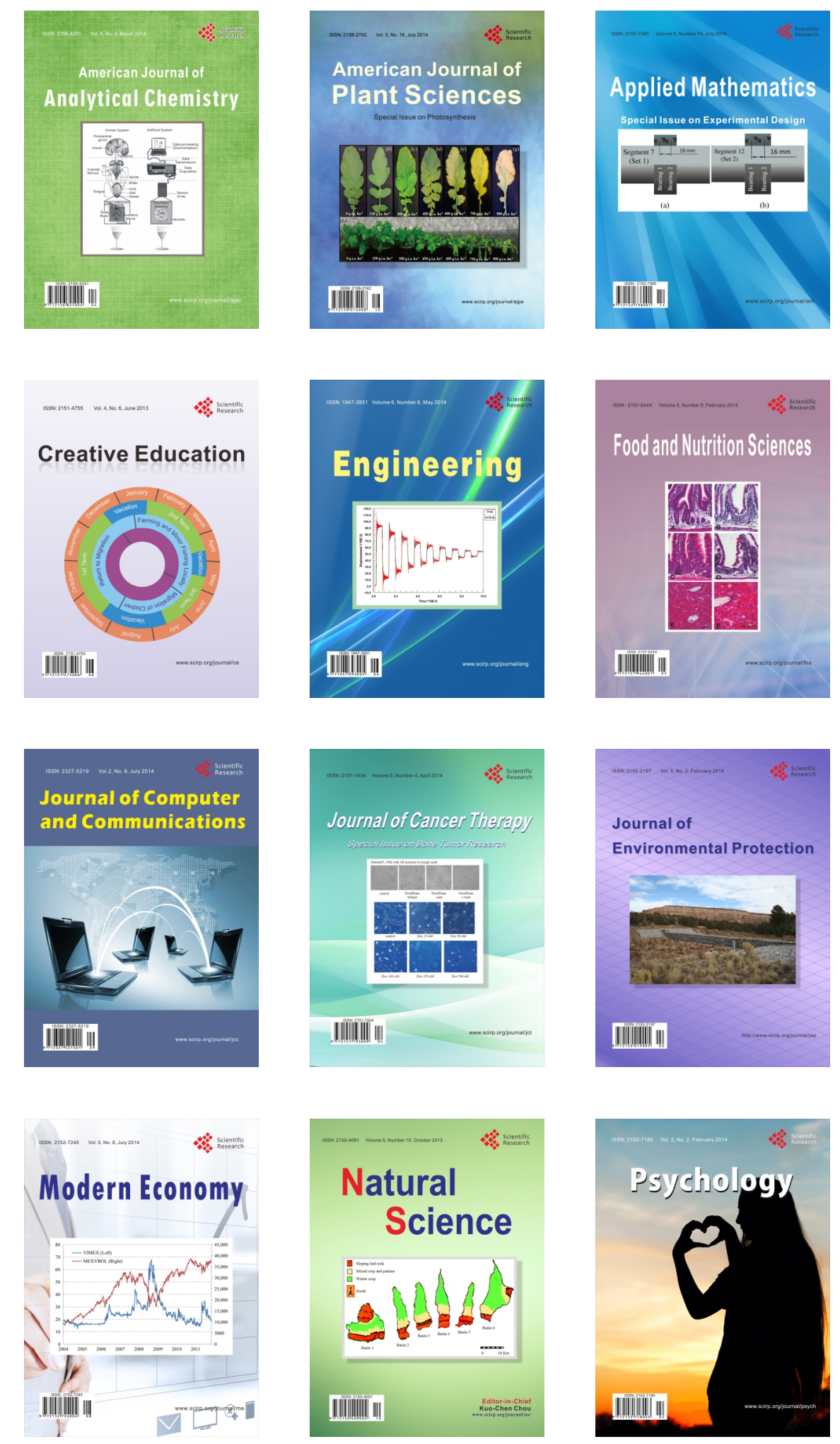